\title{
Spontaneous Coronary Artery Dissection as a Cause of Acute Coronary Syndrome in a Young Male Patient with Multiple Cardiovascular Comorbidities
}

\author{
loana Rodean¹, Elisabeta Himcinschi', Daniel Cernica1, Roxana Hodas', Elena Beganu¹, \\ Imre Benedek ${ }^{1,2}$ \\ ${ }^{1}$ Center of Advanced Research in Multimodality Cardiac Imaging, Cardio Med Medical Center, Tîrgu Mureș, Romania \\ 2 University of Medicine and Pharmacy, Tîrgu Mureș, Romania
}

\section{CORRESPONDENCE}

Elisabeta Himcinschi

Str. 22 Decembrie 1989 nr. 76

540124 Tîrgu Mureș, Romania

Tel: +40 265217333

E-mail: eli_himcinschi@yahoo.com

\section{ARTICLE HISTORY}

Received: June 11, 2017

Accepted: July 20, 2017

Ioana Rodean • Str. 22 Decembrie $1989 \mathrm{nr} .76$ 540124 Tîrgu Mureș, Romania. Tel: +40 265217333. E-mail: ioana_patricia@yahoo.com

Daniel Cernica • Str. 22 Decembrie $1989 \mathrm{nr}$. 76, 540124 Tîrgu Mureș, Romania. Tel: +40 265217333. E-mail: daniel.cernica@gmail.com

Roxana Hodas • Str. 22 Decembrie 1989 nr. 76 , 540124 Tîrgu Mureș, Romania. Tel: +40 265217333. E-mail: roxana.hodas@yahoo.ro

Elena Beganu • Str. 22 Decembrie 1989 nr. 76 , 540124 Tîrgu Mureș, Romania. Tel: +40 265217333. E-mail: beganu.elena@yahoo.com

Imre Benedek • Str. Gheorghe Marinescu nr. 38 540139 Tîrgu Mures, Romania. Tel: +40 265215551. E-mail: imrebenedek@yahoo.com
We present the case of a 34-year-old male patient, hypertensive, smoker, and diabetic, who was admitted from the Emergency Unit where he presented for typical angina pectoris with several days onset, heightened on the day of admission. In the context of typical signs and symptoms for acute coronary syndrome, the physical examination revealed arterial hypertension (blood pressure value of $140 / 70 \mathrm{mmHg}$ ) with high additional cardiovascular risk. The laboratory tests revealed elevated levels of serum biomarkers characterizing renal function (urea $58 \mathrm{mg} / \mathrm{dL}$, creatinine $1.15 \mathrm{mg} / \mathrm{dL}$ ), mild anemia (hemoglobin 9.6-11 g/dL), and a positive troponin level, while all other cardiac enzyme levels were in normal ranges. An electrocardiogram was performed, which revealed normal sinus rhythm, with a frequency of 65 beats per minute, left axis deviation, hyperacute $\mathrm{T}$ waves in leads $\mathrm{V} 1$ to V4, and right bundle branch block (Panel A). In order to assess the presence of possible coronary artery lesions in this patient with a high cardiovascular risk due to multiple comorbidities, an invasive coronary angiography was performed. The examination was well-tolerated, without any complications. Upon coronary angiography, no thrombotic lesion was revealed, and one non-significant lesion was described on the anterior descending artery (40\%), without indication for revascularization. However, at this level, an unusual persistence of the iodinated contrast agent was revealed (Panel B). In order to certify the real origin of the chest pain that appeared recently in a young patient with multiple comorbidities (type 2 diabetes mellitus, high blood pressure, obesity, dyslipidemia), an optical coherence tomography (OCT) examination was performed to evaluate in detail the coronary system and to detect a possible vulnerable plaque responsible for the symptoms. The OCT examination described a $2 \mathrm{~cm}$ long vulnerable plaque with inflammatory cells and spontaneous dissec- 


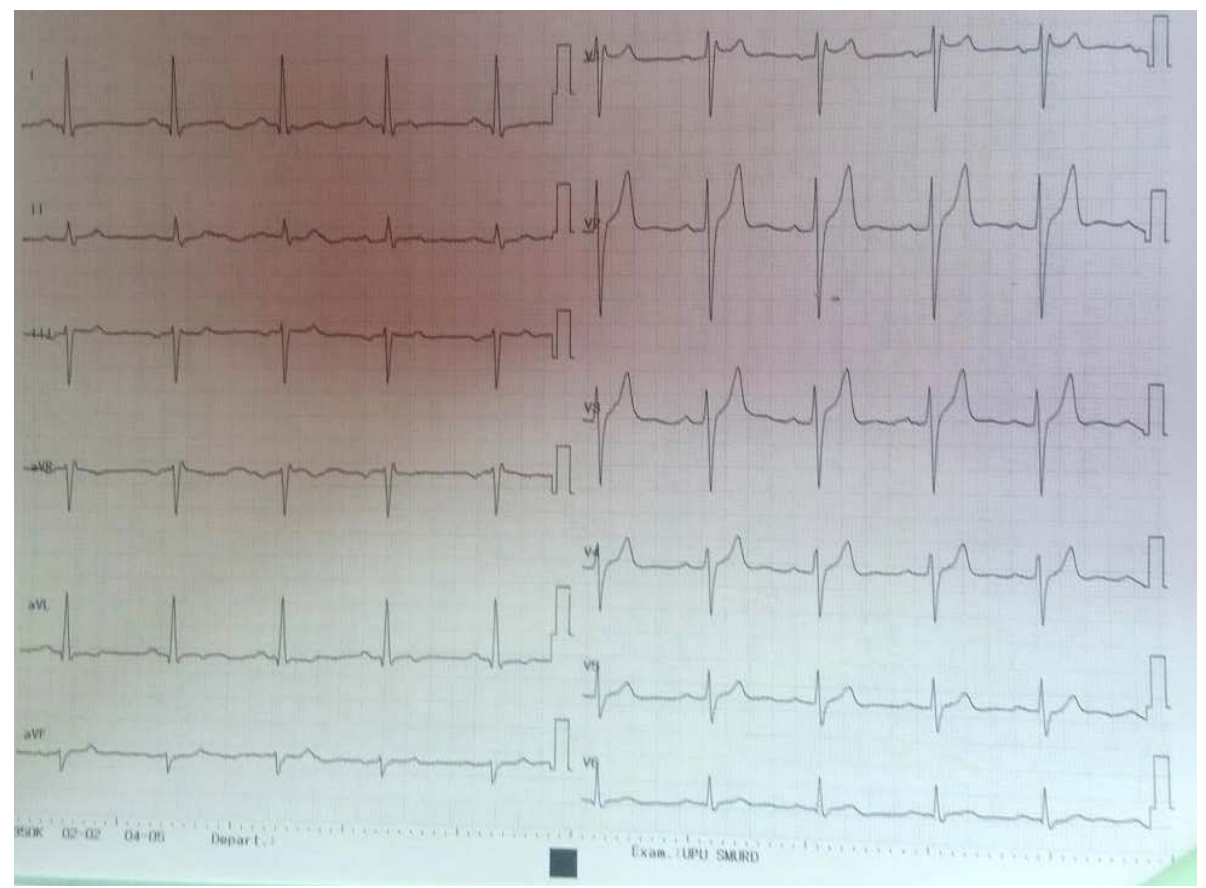

PANEL A. Electrocardiogram showing normal sinus rhythm, with a frequency of 65 beats per minute, left axis deviation, hyperacute $\mathrm{T}$ waves in $\mathrm{V} 1-\mathrm{V} 4$, right bundle branch block

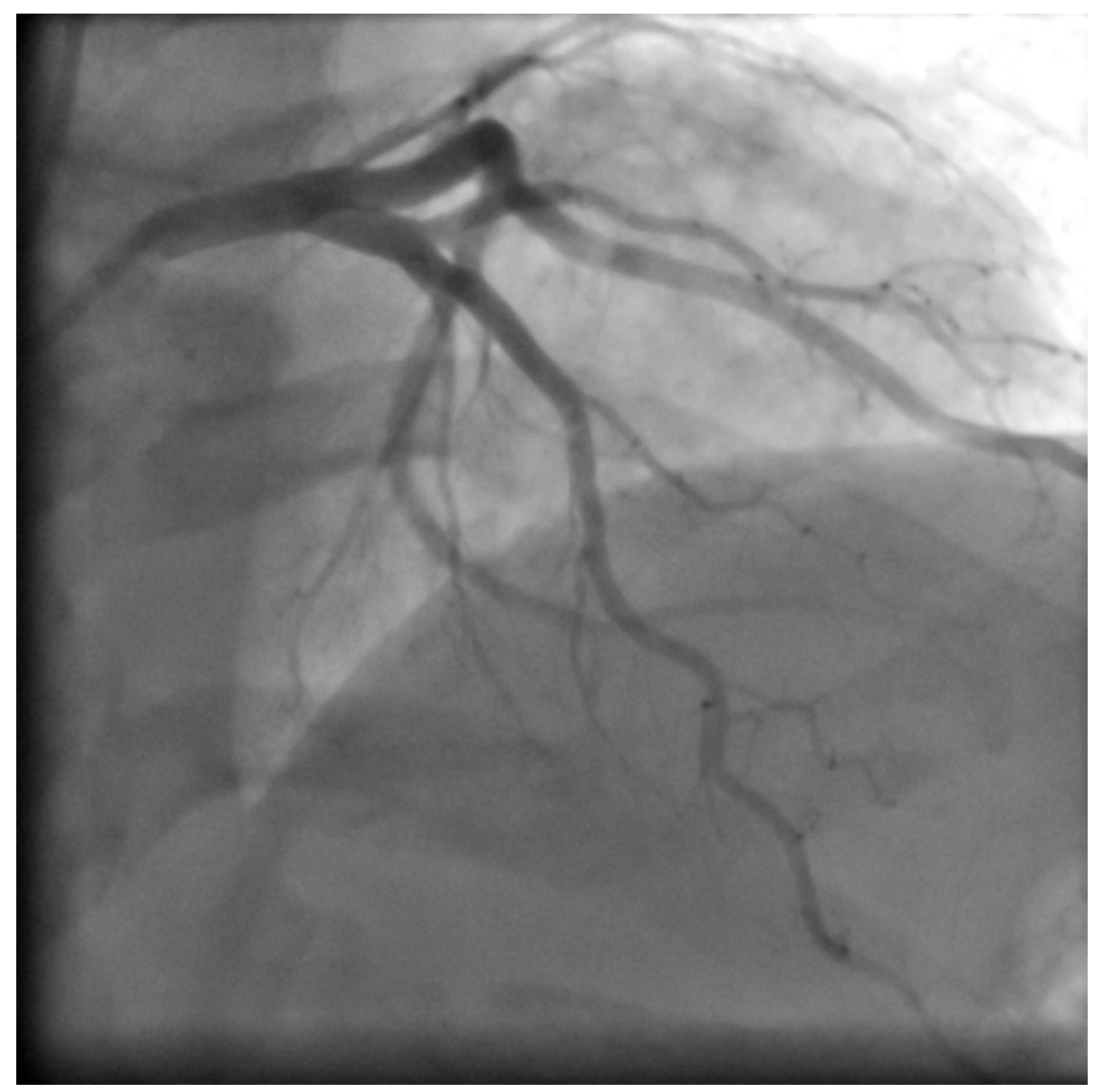

PANEL B. Coronary angiography showing no thrombotic lesion and one non-significant lesion on the anterior descending artery (40\%), without any revascularization indication 

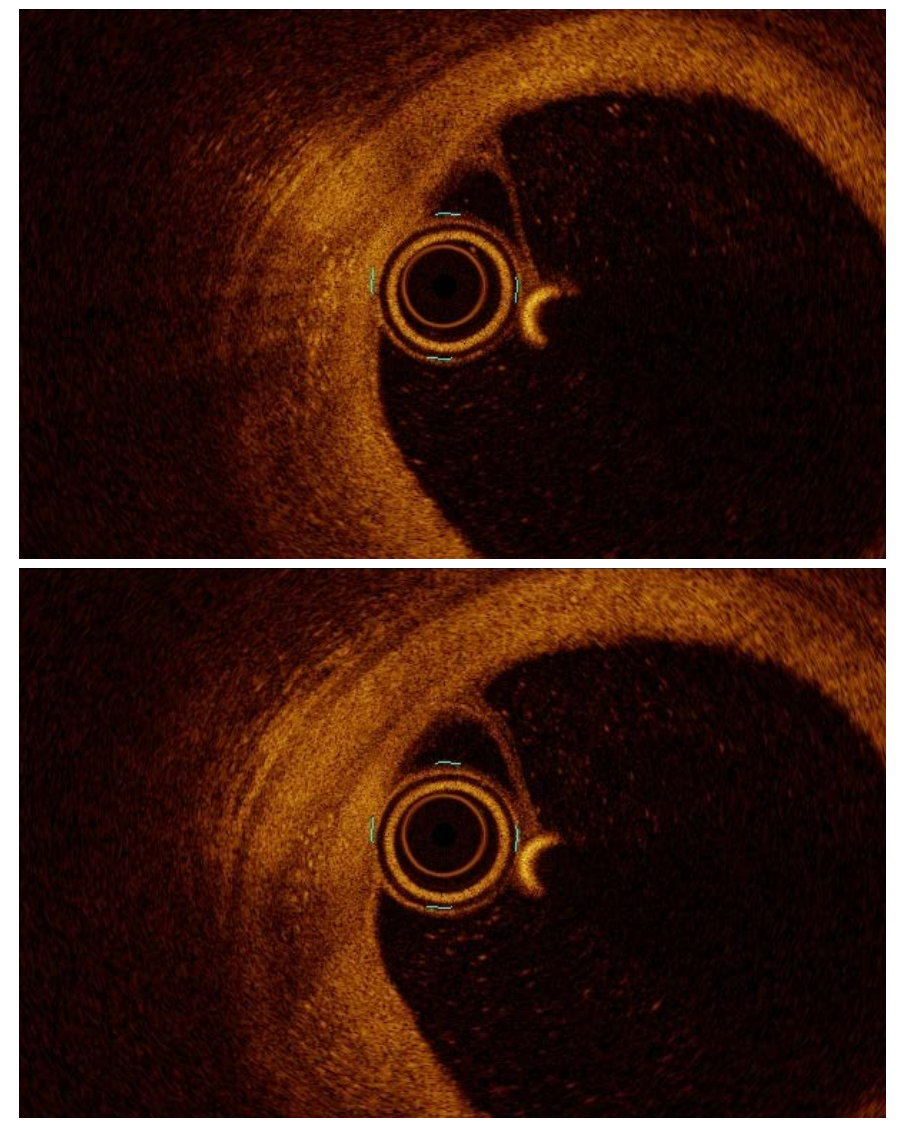

PANEL C. OCT images showing a vulnerable plaque with inflammatory cells and spontaneous dissection in the first segment of the anterior descending artery

tion that most likely occurred through an intravascular vasa vasorum rupture within the first segment of the anterior descending artery (Panel C). During hospitalization, the patient had received a conservative pharmacological treatment with dual antiplatelet therapy (Aspirin $75 \mathrm{mg}$ per day, Ticagrelor $90 \mathrm{mg}$, two times per day), statins (Rosuvastatine $20 \mathrm{mg}$ daily), beta-blocker (Carvedilol $6.25 \mathrm{mg}$, two times per day), angiotensin-converting enzyme inhibitor (Ramipril $5 \mathrm{mg}$, two times per day), which led to a significant improvement in his symptoms.

The patient agreed to the publication of his data, and the institution where the patient had been admitted, approved the publication of the case.

Acute myocardial infarction is an exceptional diagnostic entity in young adults. Generally, young coronary artery disease patients have risk factors such as chronic smoking, hypertension, and diabetes, and a significant percentage of these patients present with angiographically normal or near-normal coronary arteries. ${ }^{1}$ Acute myocardial infarction may be caused by spontaneous coronary artery dissection (SCAD). SCAD is defined by non-traumatic or non-iatrogenic separation of the coronary artery wall associated with intramural hematoma, which appears mostly in young and middle-aged patients, especially in women. The diagnosis can be difficult, and in many cases it starts from a clinical suspicion. Coronary angiography has some limitations in identifying the modifications that affect the artery wall. Advanced new imaging techniques, such as OCT and intravascular ultrasound (IVUS), are useful in visualizing the intimal disruption, intramural hematoma, or the false lumen, three important elements for the diagnosis of SCAD. Most frequently, SCAD occurs in the left coronary artery and its branches (45-61\%), followed by the circumflex artery (15-45\%), the right coronary artery $(10-39 \%)$, and the left main artery $(0-4 \%)$. Recent guidelines do not recommend stent implantation due to the risk of stent malposition, and revascularization is only recommended to patients with recurrent angina. Conservative therapy might be useful because SCAD tends to present spontaneous vessel healing. Prognosis in an acute coronary syndrome with SCAD is better compared with cases without SCAD, but there is a high risk of recurrence in these patients. ${ }^{2-4}$

\section{CONFLICT OF INTEREST}

Nothing to declare.

\section{REFERENCES}

1. Ralidis LS, Gialeraki A, Triantafyllis AS, et al. Characteristics and Long Term Prognosis of Patients $\leq 35$ Years of Age with ST Segment Elevation Myocardial Infarction and "Normal or Near Normal" Coronary Arteries. Am J Cardiol. 2017; pii:S0002-9149(17)30942-6.

2. Vandamme M, De Backer T, Drieghe B, Devos D, Gevaert S. The spectrum of spontaneous coronary artery dissection: illustrated review of the literature. Acta Cardiol. 2017;28:1-11.

3. Meng PN, Xu C, You W, et al. Spontaneous Coronary Artery Dissection as a Cause of Acute Myocardial Infarction in Young Female Population: A Single-center Study. Chinese Medical Journal. 2017;130:1534-1539.

4. Kim Y, Deharo P, Adlam D, Baumbach A, Johnson TW. The role of optica coherence tomography in decision making during the acute phase of spontaneous coronary artery dissection. Int J Cardiol Heart Vasc. 2016;14:6-7. 